\section{Asthma admissions, smoking bans and administrative databases}

We read with great interest the recent paper by Sims et al, ${ }^{1}$ wherein they identified a clinically and statistically significant reduction in admissions with asthma following the implementation of a workplace smoking ban in the UK, independent of prevailing temporal trends and other measureable confounding factors. We welcome this important addition to the evidence base in this area, and endorse the authors' view that this work addresses important deficiencies in previously published data from our group and others. ${ }^{2} 3$

However, we were surprised that an important limitation of any study using administrative databases for clinicoepidemiological research was not addressedthat of misclassification bias. In particular, we would be concerned that subjects admitted with acute bronchitis, communityacquired pneumonia, or smoking-related chronic obstructive lung disease may be misclassified as patients with asthma or vice versa. In our own study, we attempted to address this deficiency by assessing overall admissions due to respiratory disease as a primary outcome, with individual respiratory diagnoses as prespecified secondary outcomes. ${ }^{2}$ We identified a significant reduction in respiratory admissions as a whole, with a corresponding rather dramatic diminution of admissions classified as being due to asthma.

Prior studies from the USA ${ }^{4}$ suggest that administrative data may be highly specific, but insensitive for a diagnosis of asthma, while a UK-based study ${ }^{5}$ found asthma admissions to be misclassified in $9-14 \%$ of cases. Thus, what evidence is available suggests that substantial misclassification bias is a genuine risk in studies such as this.

The authors are to be congratulated on a thorough and otherwise highly robust interrogation of the effects of antitobacco legislation on respiratory health, but we feel that this important limitation should at the very least be acknowledged, and ideally-if the authors have supporting data-refuted.

Brian D Kent, ${ }^{1,2}$ Stephen J Lane, ${ }^{2}$ Edward D Moloney ${ }^{2}$

'Pulmonary and Sleep Disorders Unit, St. Vincent's University Hospital, Dublin, Ireland

${ }^{2}$ Department of Respiratory Medicine, Adelaide \&

Meath Hospital, Tallaght, Dublin, Ireland

Correspondence to Dr Brian Kent, Pulmonary and Sleep Disorders Unit, St. Vincent's University Hospital, Dublin D4, Ireland; Brian.kent@ucd.ie

Contributors BDK, SJL and EDM conceived of, and drafted this manuscript.

Competing interests None.

Provenance and peer review Not commissioned; internally peer reviewed.

To cite Kent BD, Lane SJ, Moloney E D. Thorax 2013;68:1166.

Received 12 July 2013

Accepted 5 August 2013

Published Online First 26 August 2013

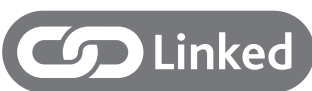

- http://dx.doi.org/10.1136/thoraxjnl-2012-202841

- http://dx.doi.org/10.1136/thoraxjnl-2013-204371

Thorax 2013:68:1166.

doi:10.1136/thoraxjnl-2013-204183

\section{REFERENCES}

1 Sims M, Maxwell R, Gilmore A. Short-term impact of the smokefree legislation in England on emergency hospital admissions for asthma among adults: a population-based study. Thorax 2013;68:619-24.
2 Kent BD, Sulaiman I, Nicholson TT, et al. Acute pulmonary admissions following implementation of a national workplace smoking ban. Chest 2012;142:673-9.

3 Rayens MK, Burkhart PV, Zhang M, et al. Reduction in asthma-related emergency department visits after implementation of a smoke-free law. J Allergy Clin Immunol 2008;122:537-41.

4 Wilchesky M, Tamblyn RM, Huang A. Validation of diagnostic codes within medical services claims. J Clin Epidemiol 2004;57:131-41.

5 Dixon J, Sanderson C, Elliott P, et al. Assessment of the reproducibility of clinical coding in routinely collected hospital activity data: a study in two hospitals. J Public Health Med 1998;20:63-9. 